\title{
ALAÍDE FOPPA Y ALBA DE CÉSPEDES: TRADUCTORAS Y MEDIADORAS CULTURALES EN MOVIMIENTO
}

\author{
Silvia M. GIANNI \\ Università degli Studi di Milano-Bicocca
}

\begin{abstract}
Alaíde Foppa y Alba de Céspedes transitaron por una multiplicidad de espacios geográficos, culturales e identitarios en los cuales desarrollaron sus creaciones literarias, tejieron redes y promovieron ámbitos donde hicieron confluir saberes y quehaceres diferentes. El nomadismo que caracterizó sus vidas y los procesos históricos que las permearon dieron origen a una escritura, a la participación intelectual y a una promoción cultural con marcados rasgos globales. Este artículo ahonda en el papel que desempeñaron las dos intelectuales como mediadoras entre mundos culturales distintos y en el afecto como elemento relevante, tanto para el desarrollo de sus prácticas como para la elección del lugar donde sentir sus arraigos.
\end{abstract}

PALABRAS CLAVE: mediación cultural, traducción, nomadismo.

\section{Alaíde Foppa and Alba de Céspedes: Translators and Cultural Mediators on the Move}

Alaíde Foppa and Alba de Céspedes moved through a multiplicity of geographical, cultural and identity-based spaces in which they developed their literary creations, weaved networks and promoted spheres where they brought together different knowledges and activities. The nomadism that characterised their lives and the historical processes that permeated them gave rise to writing, intellectual participation and cultural promotion with marked global traits. This article delves into the role played by the two intellectuals as mediators between different cultural worlds and into affection as a relevant element, both for the development of their practices and for the choice of the place where they felt their roots.

KEY WORDS: cultural mediation, translation, nomadism.

Alaíde Foppa (1914-1980) y Alba de Céspedes (1911-1997) hicieron de la movilidad física, cultural y profesional el rasgo característico de sus vidas; el tránsito a través de múltiples territorios y realidades geográficas, político-sociales, culturales y lingüísticas las llevó a desarrollar actividades profesionales multidimensionales donde lograron canalizar un intenso tráfico de saberes. Europeas por nacimiento y por procedencia de uno de los padres, las dos escritoras, pese a sus diferencias, evidencian el mismo compromiso con la literatura y la sociedad, la misma dedicación a la promoción de redes y espacios culturales de intercambio y a la globalización de su trabajo intelectual, siempre al lado de las causas emancipadoras.

Gianni, Silvia M. (2021), "Alaíde Foppa y Alba De Céspedes: traductoras y mediadoras culturales en movimiento", Lectora, 27: 107-125. ISSN: 1136-5781 D.O.I.: 10.1344/Lectora2021.27.5, gianni.silvia@gmail.com

Recepció: 15 de desembre de 2020 - Acceptació: 18 de maig de 2021 
Comparten el hecho de nacer y formarse fuera del espacio centroamericano y caribeño, ${ }^{1}$ así como el haber escogido estas áreas para desarrollar -o ahondar- su producción literaria y su quehacer intelectual. Alaíde Foppa nace en Barcelona, se forma en Italia, donde comienza a incursionar en el terreno literario, para luego ir a vivir a Francia y Bélgica, países en los que continúa sus estudios, y sucesivamente mudarse a Guatemala, tierra de origen de su madre. El regreso de Foppa a Guatemala se encuentra marcado por su participación en los proyectos sociales y culturales desarrollados durante la llamada primavera democrática (1944-1954), identificándose plenamente con el nuevo proceso político. Tras el derrocamiento del gobierno de Jacobo Árbenz en 1954 y el exilio de su marido Alfonso Solórzano, Alaíde Foppa llega a México, territorio privilegiado para la creación poética y el ejercicio de otras prácticas culturales, sin, por esto, dejar de considerar a Guatemala como su espacio de referencia. Por lo que se refiere a Alba de Céspedes, Italia y Francia son sus espacios de origen, formación y producción, mientras que Cuba representa un "viaje a la semilla", ya que en la isla articula una identidad política $y$, a la vez, desarrolla un proceso de memoria individual y colectiva. A este llamado a sus raíces y al apoyo a la causa cubana, dedica los últimos veinte años de su vida.

Por lo tanto, a ambas intelectuales las une el concepto "salir": salir de la tierra natal y de los lugares de formación; salir de su lengua; salir de la casa y de los roles tradicionales atribuidos a las mujeres en la vida y en la producción literaria; salir de un específico campo de la producción cultural para abarcar una pluralidad de dimensiones que espacian desde la creación narrativa y poética hasta la labor periodística y el activismo político, la promoción editorial y la traducción. En el caso de Alaíde Foppa "salir" significa también una separación de su clase social privilegiada para abrazar ideales progresistas. En su movilidad física, cultural y profesional las dos autoras convierten la errancia ${ }^{2}$ en una oportunidad para crear espacios culturales abiertos al otro, que permiten propiciar la ampliación y la distribución de sus labores intelectuales y formar redes y/o comunidades alrededor de un nuevo modo de ser. De esta manera, reinventan lugares y espacios (Braidotti, 2008: 194) y diversifican sus prácticas, instaurando diálogos polifónicos con voces, ámbitos y geografías diferentes.

La interconexión y los desplazamientos que caracterizan sus vidas y actividades nos acercan a su quehacer cultural ahondando en la movilidad, y no en los

\footnotetext{
${ }^{1}$ Si bien Cuba no pertenece a la región centroamericana, acojo la idea de "pensar América Central y el Caribe como cierta unidad - aunque sea en la diferencia y contradictoria- y entenderlas en todas sus dimensiones, su multiplicidad y diversidad" (Mackenbach, 2008: 107-108).

${ }^{2}$ Como sujetos errantes, salen a la búsqueda de unión y fusión comunitaria, porque, como argumenta Michel Maffesoli (2000), pueden decir que existen solo a través de la unión con los otros, y pueden comprenderse a sí mismas solo reflexionando sobre los otros (109).
}

108

Lectora, 27 (2021): 107-125. ISSN: 1136-5781 D.O.I.: 10.1344/Lectora2021.27.5 
territorios de producción; en los entrecruzamientos que establecen, y no en una determinada práctica. Es decir, nos aproximan a un enfoque transareal y transatlántico con el cual dar énfasis a los caminos, a las relaciones y comunicaciones, y con las cuales es posible analizar los diferentes procesos en sus múltiples y contradictorios contextos de vida (Ette, 2015: 1113). En esta óptica, entre las diversas labores desarrolladas por Alaíde Foppa y Alba de Céspedes, me interesa destacar el papel que han ejercido como tejedoras de redes y mediadoras entre escenarios culturales distintos a través de la escritura, la traducción -como puente para el encuentro de mundos diversos - y la promoción editorial para acercar a autores centroamericanos y caribeños al contexto europeo y viceversa.

\section{Alaíde Foppa: traductora literaria y actora en el campo cultural mexicano}

Nací en Barcelona. Mi padre era argentino y mi madre guatemalteca. Viví poco en Argentina y después en Italia. Mi padre estaba en el servicio exterior. En Italia hice mis estudios hasta secundaria. Fui a Bélgica a cursar el bachillerato y de ahí regresé a Roma donde estudié letras e historia del arte. Mis primeros acercamientos al arte y a la literatura fueron en Italia [...]. Mis vinculaciones con América Latina eran muy tenues, por mi formación europea. Guatemala fue el encuentro con la realidad latinoamericana. [...] Llegué en vísperas de la revolución democrática de 1944; viví en pocos meses ese estado de angustia y opresión que ahora se ha renovado y está cada vez peor. (Excelsior, 1981) ${ }^{3}$

Estas breves líneas reúnen la complejidad de una personalidad cosmopolita y de plurifacéticas dimensiones: poeta ${ }^{4}$, ensayista, traductora, profesora de la Facultad de Filosofía y Letras de la Universidad Nacional Autónoma de México, fundadora de la revista $\mathrm{Fem}$, creadora y conductora del primer programa feminista de la radio mexicana ("Foro de la mujer" en Radio UNAM), crítica de arte, archivista y defensora de los derechos humanos, Alaíde Foppa es una de las grandes intelectuales centroamericanas comprometidas con la emancipación social, cultural y artística de las mujeres latinoamericanas $y$, sin embargo, pese a su relevante

\footnotetext{
${ }^{3}$ Entrevista realizada por el diario mexicano Excelsior y publicada en 1981, citada por Carmen Lugo en "Semblanza de Alaíde Foppa" publicada en Doble Jornada en diciembre de 1987.

${ }^{4}$ Su obra poética se reúne en las colecciones: Poesía (1945), La sin ventura (1955), Los dedos de mi mano (1958), Aunque es de noche (1959), Guirnalda de primavera (1965), Elogio de mi cuerpo (1970), Las palabras y el tiempo (1979).
} 
presencia en la escena continental, sigue siendo no suficientemente conocida. ${ }^{5}$ Alaíde Foppa construye experiencias profesionales diversas, a la par que adquiere un capital cultural importante: las lenguas. Foppa domina plenamente el español, el italiano, el francés y el inglés, que le permitirán ejercer de traductora.

Su nomadismo implica continuas despedidas. Un índice para entender esas rupturas lo constituye el número de casas que abandona - cincuenta y ocho en total, recuerda Poniatowska (1990: 4) —, cada vez liberándolas de todo lo que contienen. Desde los códigos poéticos, Foppa expresa el sufrimiento por cada partida que se mezcla con la nostalgia por todo lo que queda encerrado en estos espacios solo aparentemente dejados vacíos, pero que encierran vidas y afectos, como se evidencia en los versos de "Adiós":

Con los ojos de la despedida

os vi aquel día, cosas de nuestra vida.

Con los ojos de la despedida, la vida parecía una cosa perdida.

La casa estaba vacía

en la hora de la despedida, y sin embargo quedaban

las cosas de nuestra vida. (2018: 127)

Sin embargo, a la nostalgia por el distanciamiento constante de sitios y espacios amados, se sobrepone la apertura de nuevos horizontes: Foppa es consciente de "ser otra constantemente" y sabe que su ser se construye entre desarraigos, guerras y una pluralidad de prácticas culturales. México es la tierra que la acoge y donde expresa, en gran mayoría, su poliedricidad de prácticas, entre ellas la promoción del programa radial "Foro de la mujer" y la publicación de Fem, primera

\footnotetext{
${ }^{5}$ Los estudios sobre su obra y su figura quedan relegados, especialmente, a México y Guatemala. Solo en los últimos años han empezado a publicarse estudios sobre sus obras y su quehacer intelectual. Entre otros, cabe mencionar el dossier de 2004 de La Jornada, "Triple Jornada"; Volando bajito. Little Low Flying, de Alicia Portnoy (2005); Alaíde Foppa. El eco de tu nombre, de Gilda Salinas (2010); el documental Alaíde Foppa, La sin ventura (2014), dirigido por Maricarmen de Lara y Leopoldo Best; Otro modo de ser, de Guisela López (2016); y el número especial de GaZeta (Guatemala, 2020) en ocasión del 40 aniversario de la desaparición de Foppa, editado por Mónica Albizúrez.

6 "Mi vida / es un destierro sin retorno. / No tuvo casa/ mi errante infancia perdida, / no tiene tierra/ mi destierro. / Mi vida navegó/ en nave de nostalgia" (2018: 135). Estos versos de "Destierro" (1959) manifiestan la consciencia de su perenne nomadismo.
}

110

Lectora, 27 (2021): 107-125. ISSN: 1136-5781 D.O.I.: 10.1344/Lectora2021.27.5 
revista feminista en América Latina, en la que el compromiso político se combina con el rigor de una producción teórica, que considera la base fundamental para una real emancipación. Fem es el espacio desde el cual Foppa promueve la constitución de un grupo solidario y atento a las luchas latinoamericanas en búsqueda de la liberación de los diferentes tipos de opresión. En la revista Fem se cuestiona el patriarcado, el racismo, el contexto poscolonial, las dictaduras y el atropello de los derechos humanos a partir de una postura intelectual que actúa como generadora de discursos y creación de redes culturales, basándose en la unidad de las demandas desde la diversidad de las posiciones. Especialmente, a partir de la publicación del quinto número, empieza bajo su coordinación una experiencia de dirección colectiva femenina. Se trata de un espacio de conjunción social y afectiva (Maíz, 2017: 37) que permea de energía emocional el funcionamiento reticular, ya que las emociones pueden considerarse factores determinantes en la constitución, consolidación y demarcación de una red (Maíz, 2017: 33).

Pero además de esa conciencia del trabajo colectivo y horizontal en Fem, me interesa destacar el rol de Foppa como mediadora de culturas a través de su labor de traductora. ${ }^{7}$ Mujer plurilingüe, traduce en italiano, francés y español en ambas direcciones, y del inglés al español. El ejercicio de la traducción lo realiza Foppa como profesión que le permite obtener compensación económica, pero también traduce voluntariamente poesía y prosa, motivada por la convicción de poner en contacto universos lejanos que considera acomunados por las mismas indagaciones y tormentos humanos. Pasar de una lengua a otra implica reformular universos conceptuales, reinventar culturas y recentralizar la identidad (Arduini, 2020: 24). Miembro de dos comunidades, el traductor es a la vez receptor en la lengua de partida y emisor en la lengua de llegada (68). Esta doble función, por tanto, supone asumir nuevas concepciones y reconocer la equidad-igualdad entre las dos lenguas, en el deseo de definir el propio ser en relación con el otro. Consiste en

hacer justicia al espíritu extraño; es instaurar la justa distancia entre cuerpos lingüísticos. Tu lengua es tan importante como la mía. Es la fórmula de la equidad-igualdad. La fórmula de la diversidad reconocida. [...] que es la fórmula misma de la justicia en el campo de la traducción. (Ricœur, 2001: 40)

Se trata de un reconocimiento mutuo que permite superar la tensión entre lo propio y lo ajeno, reflexionar sobre cómo hospedar lo que nos parece incomprensible y empezar así a construir una relación con él. En esta concepción de

\footnotetext{
${ }^{7}$ Los estudios sobre la actividad de traducción de Foppa son sumamente escasos. Una aproximación a este aspecto la ofrece el ensayo de An Van Hecke (2018).
} 
traducción hay un deseo de relación con el otro, reconocerlo e incluirlo en una relación de amistad (Arduini: 63). En el encuentro con el otro es posible reconocer la diferencia y superar nuestras limitaciones. Siguiendo a Ricœur, la traducción es un principio general de apertura a una pluralidad de discursos que garantiza la extrañeza del yo para acoger mejor al otro; es un camino que promueve la hospitalidad acercándonos a lo que es ajeno, diferente. Por esto el traductor no puede limitarse al paso y desplazamiento de palabras, oraciones, textos y culturas, sino que debe ampliar su rayo de acción "sumergiéndose en vastas lecturas del espíritu de una cultura, [que] el traductor desciende del texto, a la oración y la palabra" (Ricœur, 2005: 63). La traducción, vista así, es un diálogo entre lenguas y culturas, consiste en la apertura a una pluralidad de discursos con los cuales se entabla una relación de respeto y reconocimiento mutuo. Diálogo, apertura, encuentro, relación: son estos los presupuestos que caracterizan el compromiso intelectual de Foppa y que se reflejan también en su laborar de traductora.

En su interpretación en español de La poesía de Miguel Ángel (1966), Foppa patentiza su intención de promover un encuentro con el autor a través del cual dar vida a un universo poético. Se trata de una edición bilingüe ilustrada con bocetos de Miguel Ángel, que incluye treinta composiciones poéticas. La obra abre y cierra con contribuciones de Alaíde Foppa: una introducción sobre la vida y obra del artista, unas notas sobre la traducción, donde explica las dificultades encontradas y las estrategias empleadas para resolverlas; y un poema final dedicado al artista renacentista que lleva por título "A Miguel Ángel. En el IV centenario de su muerte".

La realización del proyecto enfrenta la dificultad de encontrar editores dispuestos a publicar una obra dirigida a un público restringido. Los méritos pictóricos y escultóricos de Buonarroti son reconocidos universalmente; no puede decirse lo mismo de su creación poética, que se aleja de la imagen de potencia, fuerza y vigor físico que emana de sus obras plásticas. Foppa lo evidencia en sus anotaciones a la edición traducida: "Es posible que la poesía fuera postergada en el elogio y casi dejada a un lado, porque no correspondía a la imagen de creador poderoso que evoca su arte, ya que la poesía de Miguel Ángel expresa casi lo contrario: la debilidad del hombre, su impotencia, su desdicha, su esclavitud" (Foppa, 1966: 9).

La traducción de los versos plantea a la autora la necesidad de escoger qué tipo de traductora quiere ser, si prefiere mantener la literalidad del texto o si elige inclinarse por la reinterpretación, en clave sustancialmente poética, operando una serie de variaciones sin alterar el verso y sin afectar los sentimientos que los impregnan. La disyuntiva está presente en la versión al castellano: en la introducción la autora ofrece algunas traducciones literales de breves poemas como muestra de las dificultades encontradas, pero en la edición prevalece su concepción de reinterpretación poética: "Sus ásperas y difíciles rimas hacen casi imposible una

112

Lectora, 27 (2021): 107-125. ISSN: 1136-5781 D.O.I.: 10.1344/Lectora2021.27.5 
traducción en verso, pero bastan algunos fragmentos, en traducción literal, para dar una idea de lo que puede ser en Miguel Ángel un desahogo cargado de expresiones prosaicas, en violento contraste con el alto vuelo que en otros momentos alcanza su fantasía" (Foppa, 1966: 21). En otros casos, se decide por intervenciones métricas que no alteren la medida del verso, lo que muestra la predilección por el respeto de la forma poética, pero también la importancia de recontextualizar y personalizar el verso, combinando la intención del autor con las habilidades de una traductora que es también poeta y tiene una formación en estudios clásicos y de retórica: "En otros poemas de corte más libre (fragmentos, esbozos, o sonetos inconclusos), he cambiado a veces consonantes por asonantes sin alterar la medida del verso y, muy poco, los acentos" (Foppa, 1966: 28). La traductora respeta plenamente tanto la versificación como la rima según el esquema clásico del soneto italiano compuesto por cuatro versos en rima cruzada, como se aprecia en la traducción del soneto de Miguel Ángel dedicado a Tomaso de' Cavalieri:

Si casto amor, si caridad superna, si a dos amantes la fortuna iguala, si lo mismo les duele suerte mala, si única voluntad ya los gobierna;

si en dos cuerpos un alma se hizo eterna que ambos levanta al cielo con su ala, si del Amor dorada flecha cala dos pechos a la vez sin que discierna; (Foppa, 1966: 50)

S'un casto amor, s'una pietà superna, s'una fortuna infra dua amanti equale, s'un'aspra sorte all'un dell'altro cale, s'un spirto, s'un voler duo cor governa;

s'un'anima in duo corpi è fatta etterna, ambo levando al cielo e con pari ale, s'Amor d'un colpo e d'un dorato strale le viscer di duo petti arda e discerna; ${ }^{8}$

\footnotetext{
${ }^{8}$ Miguel Ángel conoció al joven aristocrático Tomaso de' Cavalieri en Roma. Fue un encuentro muy significativo para Buonarroti, como lo testimonian las numerosas epístolas intercambiadas entre los dos hombres desde las cuales se destaca una implicación afectiva muy profunda.
} 
La afinidad con el poema traducido se expresa a través del respeto por la forma poética pero también por los sentimientos que impregnan los versos de Miguel Ángel. En efecto, las creaciones líricas de Buonarroti dan voz a una intimidad afectiva, con la cual se pone en relación la profundidad con la superficie, lo que da vida a una relación entre lo privado y lo público. Esta intimidad, este vínculo entre sí misma y otros representa un elemento central, es la idea de relación que se establece entre poeta y traductor y entre una cultura y otra, aspecto que está plasmado en la práctica traductora de Foppa; por esto, el continuo trabajo de contextualización - "sumergiéndose en vastas lecturas del espíritu de una cultura”, para volver a Ricœur (2005: 63) - favorece el acercamiento y la "acogida" del autor y sus asperezas líricas. Asimismo, el poema de la traductora dedicado al vate, incluido al final del libro, refuerza la concepción de diálogo e interacción que caracteriza su labor:
No hubo consuelo
para tu soledad,
ni respuesta para tu larga espera.
Y sólo en la hora de tu muerte
se inclinó la Piedad
con los brazos abiertos
sobre tu cansancio. (Foppa, 1966: 69)

En cuanto a la traducción de narrativa, es relevante comentar brevemente la edición en francés de El libro vacío, de Josefina Vicens, novela publicada en México, en 1958, que constituye una ruptura desde el punto de vista estético y del contenido en el panorama literario del país. La calidad literaria de la obra y la biografía de su autora ${ }^{9}$ estimulan en Foppa el interés por divulgar en Francia la novela de una escritora que siempre ha estado a contracorriente. El libro vacío verá luz en París en 1963, bajo el título Le cahier clandestin, con prólogo de Octavio Paz. Será el resultado de un esfuerzo compartido con Dominque Éluard, esposa de Paul Éluard, con cuya colaboración Foppa anteriormente había publicado en español $E l$ ave Fénix (1963).

Vicens recuerda que fue una sorpresa recibir la propuesta de traducción: "Estaba en casa de Alfonso Caso y se me acercaron Alaíde Foppa y Dominique Éluard, para preguntarme que si les permitía traducirlo al francés. Y yo de bruta, que no sabía nada de eso, y les dije: - Pero no tengo dinero [...] Y se rieron. ‘¿Quién le está pidiendo dinero?” (Toledo, González Dueñas, 2011: 30). Vincens subraya que el

\footnotetext{
${ }^{9}$ Autodidacta y enemiga del academicismo, Vicens trabajó como periodista y guionista. Su vida fue intensa y agitada, pues se casó con un amigo, José Ferrei, homosexual como ella, para escapar del control de sus respectivas familias.
}

114

Lectora, 27 (2021): 107-125. ISSN: 1136-5781 D.O.I.: 10.1344/Lectora2021.27.5 
proceso de traducción fue acompañado siempre por muestras de cariño y respeto hacia ella; cada parte le fue presentada para recibir su aprobación o para escuchar su parecer sobre la elección de determinadas palabras: "Cada quince días me llamaban y me decían: 'Mira, esta palabra en francés puede significar esto, esto o esto, ¿cuál te satisface más?'. Yo lo dejaba a su criterio y me limitaba a señalar las que yo hubiera elegido" (30). Dar a conocer en Francia la novela de Vicens es una expresión de la convicción de Foppa de entretejer vínculos constantes entre los dos continentes. También testimonia su compromiso con la calidad literaria de una propuesta estética que combina el tema de la escritura, las reflexiones alrededor del proceso creativo y las indagaciones en torno a temas como la cotidianidad, la familia, la soledad, la conciencia del paso del tiempo. Precisamente, la novela refleja el dolor de emprender el proceso de escritura, un proceso que se debate entre la necesidad de escribir y la imposibilidad de hacerlo. Quien habla es la voz narradora masculina de José García, un hombre mediocre, que desdobla su personalidad entre la urgencia de escribir y la conducción de una vida bajo estereotipos y generalizaciones.

La actividad de Alaíde Foppa como traductora va más allá de seguir creando mundos que se encuentran: incluye tramas culturales que valorizan los intercambios y profundizan una conciencia global en el terreno intelectual. No obstante, pese a esta conciencia global, Guatemala sigue representando el punto fijo de su interés. Durante los años en México, la poeta no deja de mantener intensos lazos afectivos e intelectuales con ese país; más aún, su casa en la capital mexicana es un lugar de encuentro para el exilio guatemalteco y allí se reúnen, entre otros, Augusto Monterroso, Miguel Ángel Asturias y Carlos Illescas. Foppa también promueve la difusión de las pinturas y esculturas de Elmar René Rojas y Roberto González Goyri; e ilustra su poemario Los dedos de mi mano con dibujos de Dagoberto Vásquez. ${ }^{10}$ También colabora con el periódico guatemalteco El Imparcial, con la columna "Cartas de México". Guatemala es el país donde la historia colectiva e individual de Foppa se entremezclan, es un espacio de dolor donde arraiga un afecto encarnado, es una casa donde han quedado las cosas de su vida, donde un pueblo sufrido busca su rescate. Es la tierra donde vive su madre, adonde han regresado tres de sus hijos para involucrarse en la lucha contra la dictadura militar, donde uno de ellos ha muerto en combate en 1980, pocos meses antes de que Foppa volviera a Guatemala para visitar a su madre y fuera secuestrada, desaparecida $\mathrm{y}$ asesinada.

\footnotetext{
${ }^{10}$ La mayoría de los poemarios de Foppa tiene ilustraciones, muestra ulterior de la confluencia entre prácticas culturales distintas.
} 


\section{Alba de Céspedes: agente en los procesos editoriales globales y compromiso político}

La vida intelectual, literaria y personal de Alba de Céspedes se deshilvana en tres sitios de escritura y de experiencia: Roma, París y Cuba. Roma es la ciudad natal, el lugar de formación y del compromiso social y político, la ciudad de su madre y de su lengua materna, como atestigua la mayoría de sus obras escritas en italiano. París es donde escoge vivir a partir de comienzos de la década de 1950 y donde intensifica su vida intelectual como miembro de una comunidad literaria que la acoge sin reservas. El francés se convierte en su segunda lengua de escritura. Sobresalen, en tal sentido, la compilación de poemas Chansons des filles de mai ${ }^{11}$ (1968) y la novela Sans autre lieu que la nuit (1973), ambas obras publicadas bajo el sello Seuil, editorial con la que estrecha una intensa colaboración. Finalmente, Cuba constituye la tierra que De Céspedes elige para sentar su identidad, el lugar que prefiere por la sangre paterna, por el apellido que lleva y "por sus glorias y dolores, por todo lo que le ha costado y sigue costando a sus hijos por su sagrado derecho de existir" (De Céspedes, 2011a: 1559). En Cuba, se gesta el proyecto de escribir una novela al que consagra muchos años de su existencia. Con este propósito emprende un meticuloso proceso de organización de la memoria — personal y familiar - con el objetivo de entrelazar sus recuerdos y sus interpretaciones con los acontecimientos de la historia cubana, para que el presente y el pasado puedan confluir en el futuro, es decir, en la experiencia de emancipación representada por la Revolución cubana en la que De Céspedes quiere involucrarse activamente por medio de su trabajo intelectual (Gianni, 2013: 25).

Hija de Carlos Manuel de Céspedes y Quesada, en aquel entonces embajador de Cuba en Italia, y de la italiana Laura Bertini; nieta del "padre de la patria" cubana -Carlos Manuel de Céspedes del Castillo_, nace el 11 de marzo de 1911, en Roma, donde comienza su formación. ${ }^{12}$ A los quince años se casa, se traslada con su marido a París, da a luz a su hijo y se separa pocos años después. A su regreso a Roma, Alba de Céspedes profundiza el camino de emancipación como mujer independiente y se desarrolla como activista de los derechos civiles y políticos. En estos años empieza a escribir algunos cuentos, pero es con la novela Nessuno torna indietro (Mondadori, 1938) que alcanza el reconocimiento de la crítica y del

\footnotetext{
${ }^{11}$ Estando en París en el periodo de la rebelión juvenil de mayo de 1968, compila esta colección de poemas en los que pone de manifiesto la personalidad de las muchas figuras femeninas protagonistas de la revuelta, dando espacio al entusiasmo, a la esperanza, a los nuevos descubrimientos, así como a miedos y ambigüedades que las atravesaron. Ella misma, en 1970, traduce al italiano la obra para la edición de Mondadori.

${ }^{12}$ Alba de Céspedes se forma como autodidacta, pues nunca asistió a una escuela; en la biblioteca de familia empezó las primeras lecturas que le abrieron el horizonte hacia nuevas búsquedas.
}

116

Lectora, 27 (2021): 107-125. ISSN: 1136-5781 D.O.I.: 10.1344/Lectora2021.27.5 
público. Durante los años de la Segunda Guerra Mundial, se traslada primero a Abruzzo y luego a Bari, ciudad donde, bajo el pseudónimo de Clorinda, dirige en Radio Bari la transmisión "Italia combatte", de marcado compromiso antifascista. Dos veces encarcelada por el régimen de Mussolini, en 1944 regresa a Roma, ahora liberada, para retomar la actividad periodística; funda y dirige hasta su cierre en 1948 la revista Mercurio, publicación mensual dedicada a la política, el arte y la ciencia que se propone renovar y despertar la conciencia italiana. Siempre con Mondadori, publica otras dos novelas Dalla parte di lei (1949) y Quaderno proibito (1952). En este periodo se desplaza entre Italia, Estados Unidos y La Habana, intensifica su actividad periodística — es enviada especial por Il Messaggero en Estados Unidos y en Cuba- y establece una estrecha relación con el ambiente intelectual italiano. Polifacética en sus prácticas culturales, Alba de Céspedes se mueve entre idiomas, ${ }^{13}$ géneros, continentes, países. Conjuga el periodismo con la narrativa, el activismo social, la poesía, el cine ${ }^{14}$ la promoción editorial y la traducción.

Durante los numerosos viajes a Cuba, Alba de Céspedes fomenta una amplia actividad de difusión y mediación entre escenarios culturales diferentes, como la promoción editorial - con propuestas literarias para acercar a autores caribeños al mundo europeo- y el proyecto de escritura de Con gran amor, al que me referiré más adelante. En La Habana, entra en contacto con los principales intelectuales de la isla: José Lezama Lima, Virgilio Piñera, Heberto Padilla, por mencionar algunos. En enero de 1968, participa con la delegación italiana en el Congreso Cultural de La Habana, siendo parte de la comisión "Problemas de la creación artística y del trabajo científico y técnico", donde conoce a Lezama Lima y Fernando Retamar.

Una parte de las intensas relaciones culturales entretejidas con los intelectuales cubanos, tanto en el periodo republicano como en el revolucionario, se refleja en algunos volúmenes que componen su biblioteca personal, ${ }^{15}$ en la cual aparecen, entre otros, dos obras de Dulce María Loynaz que testimonian una relación entre ambas autoras, la cual debe haberse desarrollado durante un periodo de por lo menos veinte años, según atestiguan los ejemplares de Versos (Tenerife, [s.n.],

\footnotetext{
${ }^{13}$ De Céspedes domina el italiano, francés, español e inglés, lengua que usa como corresponsal en los Estados Unidos; además conoce el alemán y el ruso.

${ }^{14}$ Colabora con el director cinematográfico Michelangelo Antonioni en la realización de Le amiche (1955), película inspirada en el cuento de Cesare Pavese "Tra donne sole".

${ }^{15}$ La biblioteca personal de Alba de Céspedes se compone de 4,630 piezas entre volúmenes, revistas y folletos. Custodiada en el Fondo Alba de Céspedes de la Fondazione Arnoldo e Alberto Mondadori de Milán desde 2009, tiene una sección nombrada "Cuba" que incluye obras dedicadas o provenientes de la isla. Sobre esta sección ver “Apuntes sobre 'lo cubano' en la biblioteca viva de Alba de Céspedes” de Yenifer Castro Viguera (2020).
} 
1947) y Carta de amor a Tuta-ank-amen (1953), dedicados a Alba de Céspedes respectivamente en 1950 y 1970 . Entre las revistas coleccionadas se destaca Orígenes, cuyo director, José Lezama Lima, dedica a la ítalo-cubana el número 38 (La Habana, 1955), elogiando "la sutileza de su inteligencia" (3).

Gracias a los fuertes vínculos profesionales y de amistad que tiene con algunos editores europeos, recomienda la publicación de Lezama Lima, Miguel Barnet, ${ }^{16}$ Alejo Carpentier y Heberto Padilla. En Italia se dirige a Alberto Mondadori, amigo con el que mantiene un intenso intercambio de cartas y quien, además, es el fundador del sello editorial Il Saggiatore, que en 1971 publicará Paraíso, de Lezama Lima; mientras que, en 1983, con Mondadori, saldrá En mi jardín pastan los héroes, de Heberto Padilla. Algunos años después, la autora estipula un contrato con Seuil para la publicación de una obra que debería recoger sus conversaciones con Fidel Castro, con quien entabla una relación cercana y quien la invita a presenciar las principales celebraciones nacionales. Sin embargo, De Céspedes deja a un lado este proyecto de publicación para dedicarse de lleno a la redacción de Con gran amor. En 1983 trabaja para la adaptación televisiva de El siglo de las luces, de Alejo Carpentier. Cuba, por tanto, entra a ser parte de los espacios europeos en los que la intelectual deshilvana su acción y promoción cultural.

Pese a la gran admiración por la Revolución cubana, la escritora orienta sus sugerencias editoriales siguiendo criterios literarios. Muestra de ello es la propuesta a Mondadori y Longanesi de dos autores polémicos con el proceso sociopolítico cubano, como son los casos de José Lezama Lima y Herberto Padilla. La intelectual no entra en las contradicciones que se abrieron entre los dos literatos y el gobierno de la isla, sino que insiste en el valor artístico de su escritura y en la convicción de que sus obras merecen ser conocidas más allá del espacio cubano, a pesar de toda controversia. El suyo es un posicionamiento autónomo que arraiga en la importancia que confiere a la calidad literaria De Céspedes no hace alusión al contexto, más bien, calla frente a la polémica suscitada y a las posiciones homofóbicas oficiales en aras de estimular la difusión literaria y cultural, más allá de sus convicciones políticas y de su plena adhesión a la causa cubana. El compromiso con el oficio literario prevalece por encima de otros criterios.

Al lado de la actividad de promoción editorial, De Céspedes madura la idea de escribir una novela cubana, proyecto que comienza a gestar a partir de los años 40, en ocasión de largas y repetidas estadías en la isla debidas a la enfermedad y muerte de su padre y a los problemas mentales de su madre, que empezaron a manifestarse tras el fallecimiento del esposo. Con el paso del tiempo, el proyecto sufre varias

\footnotetext{
${ }^{16}$ Biografía de un cimarrón, de Miguel Barnet, fue publicada en Italia por Einaudi en 1968, gracias a la mediación de Italo Calvino, a quien De Céspedes conoció en La Habana, en 1964, en ocasión del Premio Literario Casa de las Américas.
}

118

Lectora, 27 (2021): 107-125. ISSN: 1136-5781 D.O.I.: 10.1344/Lectora2021.27.5 
modificaciones, incluso al elegir los posibles títulos, hasta el definitivo Con gran amor. ${ }^{17}$ Solo en 1977 logra entregar un primer esbozo a Giannina Bertarelli, corresponsal de ANSA, la agencia de prensa italiana en La Habana, para que lo traduzca al español. Pese a dominar el español, De Céspedes escribe la novela y todas las anotaciones en italiano. ${ }^{18}$

La novela quedará inacabada debido a obstáculos atribuibles no solo a las dificultades de encontrar un equilibrio entre la historia familiar y nacional que se sobreponen a lo largo de la narración, sino también por la necesidad y ansiedad de ofrecer al lector italiano todas las explicaciones posibles para que entienda la realidad cubana y pueda así abandonar prejuicios y borrar distancias. Su labor de mediación cultural, por lo tanto, sobresale también en el proyecto de Con gran amor. En efecto, una de las grandes dificultades encontradas por la autora en la escritura de la novela ${ }^{19}$ radica en la necesidad de promover un acercamiento entre la realidad de la isla antillana y el público lector extranjero. Por esta razón da gran importancia al receptor, pues conociéndolo, sabe que este requiere determinadas aclaraciones y profundizaciones sobre temas, paisajes, vegetación y costumbres de Cuba. Consciente de la falta de conocimiento del contexto cubano, de su gente, historia y tradiciones, la novelista decide ahondar la narración en aspectos que conciernen a la cotidianidad en la isla. Describir las pequeñas cosas y la vida de todos los días, pormenorizar referencias a calles, objetos, colores y frutas, es la estratagema empleada para atraer al lector y conducirlo en un viaje de descubrimiento, haciendo hincapié en imágenes y situaciones donde pueda encontrar afinidad entre la isla y

\footnotetext{
${ }^{17}$ Una primera muestra de la intención de escribir una novela sobre Cuba data 1939. En su archivo personal se encuentra un texto mecanografiado de 1939 con el título Romanzo cubano. Sin embargo, tema, protagonista y finalidad de la obra difieren mucho de la idea que inspira Con grande amore.

${ }^{18}$ Consta que el 2 de septiembre de 1977 los fragmentos traducidos por Bertarelli fueron entregados a Rolando Rodríguez, viceministro de Cultura en Cuba, pero de estos no se han tenido mayores noticias. Las partes traducidas están conservadas en el Fondo Alba de Céspedes de la Fondazione Arnoldo e Alberto Mondadori de Milán. Por esta razón, las citas de la novela que se citan en este artículo están en italiano, poniendo en nota la traducción española de Giannina Bertarelli, que solo en parte se puede sobreponer a la versión italiana. En 2011, salió la edición cubana de Con gran amor por la editorial Unión con traducción de Mayerin Bello Valdés.

${ }^{19}$ En la nota introductoria de Con grande amore en la colección "I Meridiani” (p. 1476) se aclara que la obra no está acabada, razón por la cual la editorial Mondadori ha efectuado una selección de los materiales mecanografiados conservados en el Fondo Alba de Céspedes de la Fondazione Mondadori. Abre la sección [1.12, p. 1477] una selección de fragmentos que se consideran narrativa y formalmente más acabados y que reflejan una secuencia cronológica. A partir del fragmento 1.19 (p. 1560) se reúnen las porciones textuales menos elaboradas, pero significativamente relevantes por temática, calidad formal y finalidades narrativas.
} 
sus propios conocimientos. Al mismo tiempo, De Céspedes busca involucrar al lector mediante el despertar de sensaciones, emociones y afectos. Cada objeto cobra vida, porque vincula su representación con el trabajo con el cual ha sido realizado o con el uso que le da el cubano. Así, por ejemplo, la narradora describe las sillas mecedoras — cuyos movimientos sustituyen el abanico para mover el airey explica que las mismas tienen brazos amplios para permitir colocar un cenicero, ya que el cubano es fumador, como también para poner un vaso de jugo de fruta o de licor, especificando colores y sabores de la bebida. El empleo de la sensorialidad propicia la aproximación de Cuba al mundo de lectores/as italianos/as:

Le case, secondo la tradizione creola, avevano inferriate finemente lavorate alle finestre e nell'interno le mamparas, cioè le porte battenti di legno intagliato con le vitrales dalla decorazione romantica a medios puntos... Molti artigiani spagnoli erano venuti al seguito dei primi governatori dell'isola e i figli hanno continuato il mestiere paterno, dandogli però un carattere locale, per esempio nelle mecedoras, nei balances, cioè i seggiolini a dondolo, immancabili tutt'ora in ogni casa cubana, poiché nell'aria ferma dell'estate il movimento sostituisce quello del ventaglio. Mecedoras di mogano e canné, dai braccioli ampi per deporvi il portacenere (giacché tutti fumano a Cuba, e i vecchi più degli altri) oppure il bicchiere per $\mathrm{i}$ succhi di frutta vivacemente colorati, da quello giallo oro del mamey a quello violaceo della guayaba, che si sorbivano senza fretta per meglio gustarne il sapore: un sapore tipicamente tropicale come quello di liquori che oggi ancora si servono, e si riservano, agli amici: crema di banana, di ananas, di cacao, forti e profumatissimi. (De Céspedes, 2011a: 1504$1505)^{20}$

En este fragmento, se hace evidente la decisión de dejar en español las palabras consideradas de difícil traducción e interpretación y, para facilitar la comprensión,

\footnotetext{
20 "Las casas, según la tradición criolla, tenía rejas trabajadas con precisión en las ventanas y en el interior las mamparas, es decir puertas batientes de madera tallada con vitrales de decoración romántica a medios punto... Muchos artesanos españoles llegaron tras los primeros conquistadores de la isla y sus hijos siguieron el oficio paterno, confiriéndole un carácter local, por ejemplo en las mecedoras, en los balances, o sea asientos mecedores, que hasta hoy en día no faltan en cada casa cubana, ya que en el aire estancado del verano el movimiento sustituye el del abanico. Mecedoras de caoba y canné, con brazos amplios para apoyar el cenicero (todos fuman en Cuba, y los ancianos más que los otros), o el vaso para los batidos de fruta con colores alegres, del amarillo oro del mamey al morado de la guayaba, que se sorbían sin prisa para apreciar mejor el sabor: un sabor típicamente tropical como el de los licores que siguen sirviéndose aún hoy y que se ofrecen a los amigos: crema de banano, de piña, cacao, fuertes y muy perfumadas".
}

120

Lectora, 27 (2021): 107-125. ISSN: 1136-5781 D.O.I.: 10.1344/Lectora2021.27.5 
se añade su explicación. Los objetos o las situaciones, extrañas hasta ahora para lectores/as italianos/as, adquieren así una cierta familiaridad; la intención es tranquilizar frente a lo desconocido, pero, asimismo, se propone debilitar o, mejor, derrumbar, la hostilidad con que se presenta en Europa la realidad cubana bajo la dirección de Fidel Castro. Llevando de la mano a lectores y lectoras, "invita" a entrar en las casas cubanas para que observen sus espacios, tengan confianza y se cree empatía:

Le comunità in Italia si chiamano condomini. (La parola condominio rassicura). Sono villaggi sorti in zone verdi e ridenti. [...] Casette singole e appartamenti provvisti di cucina a gas, bagno, scaldabagno, frigorifero, televisore, e persino di un frullatore elettrico, poiché ai cubani piacciono i succhi di frutta. (De Céspedes, 2011a: 1552) ${ }^{21}$

Toda descripción responde a un deseo didáctico de enseñar la realidad cubana en todas sus facetas. Enseñar es una tarea que requiere competencia, pero también amor y ese amor se manifiesta en la emotividad de algunas narraciones, en cada detalle cotidiano y en cada episodio de la vida nacional presente y pasada. Con esta técnica, De Céspedes transporta al lector o lectora desde la colonia hasta las gestas de la independencia, desde la dictadura de Batista hasta la Revolución de 1959, y desde la Revolución hasta la actualidad. Así, la narradora se centra en la vida de su abuelo, su padre y de los héroes de la revolución, haciéndolos confluir todos en la misma realidad y confiriendo un papel primordial a las vicisitudes familiares. El intento de organización de la memoria se evidencia en las anotaciones casi obsesivas de todo lo que la narradora ve, escucha y lee. Su archivo personal conserva un material inmenso, razón que dificulta la selección a la hora de consultarlo.

Por otra parte, la necesidad de equilibrar hechos, hazañas históricas, anhelos de justicia, experiencias personales, emociones y recuerdos familiares, afecta el proceso de escritura:

Sentivo su di me tutto il perso dell'isola che io impersonavo, agli occhi di chi non la conosceva; e del resto anche quando ero all'Avana mi pareva che io sola la conoscessi veramente, benché spesso mi scambiassero per una straniera a causa del mio accento e del mio modo di vestire. Mi pareva di comprenderla meglio di chiunque altro, proprio perché la conoscevo

\footnotetext{
21 "Las comunidades en Italia se llaman 'condomini'. (La palabra 'condominio' da seguridad). Son poblados nacidos en zonas verdes y amenas. [...] Casitas y apartamentos con cocina de gas, baño, calentador de agua, frigorífico, televisor, y hasta una licuadora eléctrica, porque a los cubanos les encantan los batidos de fruta".
} 
attraverso la leggenda, la storia, la poesia... (Fondazione Arnoldo e Alberto Mondadori, Subserie “Alba I-XVIII", f. XVII.27). ${ }^{22}$

En el proceso de escritura, De Céspedes experimenta dudas sobre la novela, como se evidencia en las comunicaciones a su amigo editor Arnoldo Mondadori. En una carta De Céspedes confiesa la dificultad que encuentra para terminar su redacción: "Este es un libro que hubiera podido seguir escribiendo diez años más" (De Céspedes, 2011a: 1168). ${ }^{23}$ El deseo de escribir esta obra para afincar sus raíces es también una clara demostración de amor a Cuba: en esos años, tal vez "per grande amore, sono divenuta veramente cubana non solo sui documenti” (De Céspedes, 2011a: 1601). ${ }^{24}$

Según la autora, en Europa la invitan a abandonar la empresa, a volver a narrar y ocuparse de temas más cercanos a los intereses editoriales, a escribir sobre el amor. A este reclamo contesta: "Efectivamente escribo de amor, es más, de un gran amor. Pero ellos no comprenden o fingen que no comprenden" (De Céspedes, 2011b: 178). Adele Cambria, en una entrevista a Alba de Céspedes en 1987, subraya el deseo de volver a sus raíces manifestado por la novelista: "En aquel último encuentro en París, me di cuenta de que la escritora que yo había frecuentado en Roma en los primeros años sesenta, la mujer emancipada de quien leía libros y artículos, la nómada intrépida Alba, había buscado siempre, y aún más, como suele pasar, en los últimos años de su vida, sus propias raíces; y Cuba había llegado a ser, como dice el título, su gran amor" (Cambria, 2011: 9). ${ }^{25}$

Alba de Céspedes muere en París, en 1997, sin poder satisfacer su deseo de concluir su obra. A las dificultades ilustradas va añadida la falta de apoyo de quienes hubieran debido acompañarla y/o asesorarla en este intento ${ }^{26}$ :

\footnotetext{
22 "Sentía en mí todo el peso de la isla que representaba a los ojos de quienes no la conocían. Cuando estaba en La Habana pensaba que yo sola la conocía de verdad, a pesar de que a menudo pasara por extranjera por mi acento y mi modo de vestir. Pensaba conocerla mejor que cualquier otra persona, ya que la conocía a través de la leyenda, la historia, la poesía".

${ }^{23}$ La carta tiene fecha del 26 de mayo de 1977.

24 "Por gran amor, me hice cubana de verdad, no solo en los papeles".

${ }^{25}$ El título de la novela es la respuesta de Fidel Castro a la pregunta de la autora sobre cómo había podido avanzar tanto en la transformación de Cuba en tan poco tiempo. Castro le contestó: "Con gran amor" (Fondazione Arnoldo e Alberto Mondadori, Fondo Alba de Céspedes, Subserie "Appunti manoscritti", f.204).

${ }^{26}$ En "Con grande amore: il romanzo postumo di Alba de Céspedes", ensayo de Alessandra Riccio (2012), se analizan algunas de las dificultades encontradas para terminar la novela.
} 
¿Cómo fue posible que una gran editorial, Mondadori, que había tenido entre sus autores más conocidos y rentables un nombre como Alba de Céspedes, no la haya sostenido en aquellos últimos diez años de su existencia? En los diarios, en las cartas, la escritora pedía ayuda, buscaba a alguien que le dactilografiara las versiones del libro [...] ¿Es posible que nadie haya percibido su grito de ayuda, por más orgulloso que fuera? (Cambria, 2011: 9)

Su gran proyecto de vida y escritura queda inconcluso. El mundo editorial para el cual había trabajado tejiendo redes, propiciando intercambios y creando espacios de encuentro no le da el apoyo esperado en esta aventura. Sin embargo, la publicación póstuma de la novela inacabada deja constancia del deseo de poner en relación dos realidades cultural, social y políticamente lejanas, buscando entrelazar un vínculo con el público receptor basado en la cotidianidad y familiaridad, en gestos, emociones y acciones que promueven una suerte de lazo afectivo que favorece la interconexión. En esta actividad de mediación ocupa un papel de relieve la voluntad de la autora de divulgar la "verdad" de la causa revolucionaria.

\section{Conclusiones}

Si bien con biografías y prácticas literarias y culturales diferentes, Alaíde Foppa y Alba de Céspedes tienen en común el mismo compromiso en la construcción de un entramado para la conformación de espacios de sociabilidad e intercambio a partir de una posición de acercamiento, diálogo y acogida del otro. El movimiento y la circulación de ideas, saberes, obras y autores en los diferentes campos culturales ha dado lugar a interacciones transareales y transcontinentales donde prima la puesta en comunicación de mundos y sensibilidades diferentes que las dos intelectuales expresan, junto con otras actividades, en la labor de traducción y mediación cultural. En el desarrollo de estas prácticas, destaca un claro compromiso con la traducción y la edición literarias. En Foppa este se refleja en la elección de las obras traducidas y en la combinación de opciones de traducción con su habilidad escritural y, en especial, de poeta. En cuanto a De Céspedes, este compromiso se evidencia a través de una promoción editorial basada en criterios de selección que superan el fervor político (y emocional) con el cual apoya el proyecto de una nueva sociedad en Cuba, demostrando una cierta autonomía.

Paralelamente a aquellas labores de traducción y de edición literarias, Foppa y De Céspedes promueven conexiones y canales de transmisión para el intercambio de ideas y saberes, establecen relaciones que son constitutivas de tramas culturales donde la implicación afectiva y la circulación de una energía emocional son partes constitutivas de la conjunción social creada y de la formación de discursos (Maíz, 2017: 37). Crean así un entramado de economía afectiva (Ahmed, 2015), en el cual 
se producen determinadas emociones entendidas como prácticas culturales y sociales que determinan la construcción del mundo.

En la multidimensionalidad de sus quehaceres intelectuales desarrollados en las diversas latitudes y en los distintos momentos históricos y personales, ambas autoras evidencian un hilo común que radica en el empeño de forjar caminos de emancipación de la mujer y de promoción de la justicia. Con esta misma actitud de emancipación promueven la constitución de espacios de comunicación vinculante e interactiva para el encuentro entre lenguas y culturas, llevando a cabo acciones que involucraron sus mismos trayectos de vida. Entretejiendo vidas, cuerpos y afecto, las dos autoras profundizan sus procesos de subjetivación y consolidación identitarios (Pons Rabasa, Guerrero Mc Manus 2018: 4); construyen puentes para fomentar el intercambio comunicativo, cultural y emocional. El sentir de otros sentires, el ser afectas por contextos, coyunturas y lazos personales, se traduce en la experimentación de prácticas con las que ellas mismas lograron afectar los diferentes ámbitos culturales en los que transitaron.

\section{REFERENCIAS BIBLIOGRÁFICAS}

Ahmed, Sara (2015), La política cultural de las emociones, México, UNAM.

Arduini, Stefano (2020), Con gli occhi dell'altro. Tradurre, Milano, Jaka Book.

Braidotti, Rosi (2008), Trasposizioni. Sull'etica nomade, Roma, Luca Sassella Editore.

Cambria, Adele (2011), “Alba de Céspedes. Quel sogno di Cuba e l'ultimo rimpianto del libro che non c'è”, La Repubblica, 3 junio: 9.

Castro Viguera, Yenifer (2020), “Apuntes sobre 'lo cubano’ en la biblioteca viva de Alba de Céspedes”, Dal Mediterraneo agli Oceani. 16 mayo 2021. $<$ https://dalmediterraneoaglioceani.wordpress.com/2020/06/10/apuntes-

sobre-lo-cubano-en-la-biblioteca-viva-de-alba-de-cespedes/>

De Céspedes, Alba, (2011a), Romanzi, Milano, Arnoldo Mondadori.

-(2011b), Con gran amor, La Habana, Unión.

Ette, Ottmar (2015), "Estudios transareales y estudios transandinos", Revista Iberoamericana, LXXXI (253): 1115-1137.

Fondazione Alberto e Arnoldo Mondadori, Fondo Alba de Céspedes, Subserie "Appunti manoscritti", Milano.

—Fondo Alba de Céspedes, Subserie “Alba I-XVIII”, Milano.

Foppa, Alaíde (ed.) (1966), La poesía de Miguel Ángel, México, Finisterre editor.

-(2018), Viento de Primavera, Guatemala, Editorial Cultura. 
Gianni, Silvia Maria (2013), “Me hice cubana de verdad'. Escribir para hacerse”, Centroamericana 23.1: 23-44.

Lezama Lima, José (1955), Orígenes: Revista de Arte y Literatura 38 (XII): 3.

Loynaz, Dulce María (1947), Versos, Tenerife, Litografía A. Romero.

-(1953), Carta de amor a Tuta-ank-amen, Madrid, Colección Palma.

Lugo, Carmen (1987), "Semblanza de Alaíde Foppa", La Jornada, 6 de diciembre, 16/11/2020. <https://www.jornada.com.mx/2006/01/02/dossiers/alaide/alaide 3triple_28.htm>

Mackenbach, Werner (2008), "El Caribe y la literatura centroamericana: de la doble exclusión al doble espejo", Caribbean(s) on the Move. A TransArea Symposium, Ottmar Ette (ed.), Frankfurt, Peter Lang: 107-119.

Maffesoli, Michel (2000), Del nomadismo. Per una sociologia dell'erranza, Milano, Franco Angeli.

Maíz, Claudio (2017), "Las redes y la 'energía emocional': epistolarios latinoamericanos, afectividad y formación de discursos”, E.I.A.L-Estudios Interdisciplinarios de América Latina, 28 (1): 32-55.

Poniatowska Elena (1990), “Alaíde Foppa”, Debate feminista, 2: 4

Pons Rabasa, Alba y Siobhan Guerrero Mc Manus (coords.) (2018), Afecto, cuerpo e identidad. Reflexiones encarnadas en la investigación feminista, México, UNAM.

Riccio, Alessandra (2012), "Con grande amore: Il Romanzo Postumo Di Alba De Céspedes”, Belfagor, 67 (6): 713-20. 16/11/2020. <https://www.jstor.org/stable /26120829?seq=1>

Ricœur, Paul (2001), Lo justo 2, Madrid, Caparrós.

-(2005), Sobre la traducción. Patricia Wilson (trad.), Buenos Aires, Paidós.

Toledo, Alejandro y Daniel González Dueñas (2011), “Josefina Vicens habla de El libro vacío", La Colmena, 71:25-33.

Van Hecke, An (2018), "Poesía y traducción en el exilio: la obra de Alaíde Foppa", Cuaderno de Tradução, 38 (1): 86-105, 16/11/2020. <https://doi.org/10.5007/ 2175-7968.2018v38n1p86>

Vicens, Josefina (1963), Le cahier clandestin, Alaíde Foppa y Domique Eluard (trads.), París, Julliard. 